\title{
Seasonality and First Ever Ischemic Stroke, In Sohag University Hospital, Sohag, Egypt
}

\author{
Authors \\ Hassan M. Elnady ${ }^{1}$, Alaa Eldin Sedky ${ }^{1}$, Al-Amir Bassiony Mohamed ${ }^{1}$, \\ Mahmoud A Hegab ${ }^{2}$, Rasha Abd Elhameed Ali ${ }^{3}$, Mohamed N. Thabit ${ }^{1}$ \\ ${ }^{1}$ Department of Neurology, \\ ${ }^{3}$ Department Public Health and Community Medicine, Faculty of Medicine, Sohag University, Egypt \\ ${ }^{2}$ Geography Department- Faculty of Arts - Sohag University, Egypt \\ Corresponding Author \\ Hassan M Elnady \\ Lecturer of neurology, Department of neurology, Faculty of Medicine, Sohag University, Egypt \\ Email: elnadyhassan1974@hotmail.com Fax:0934602963\Telephone no: 0934602963
}

\begin{abstract}
Introduction: The effect of Seasonality on stroke has been reported in several regions worldwide. Nevertheless, there is inadequate data related to these phenomena in other areas. The aim of the present study was to investigate the possible effect of seasonality on first ever ischemic stroke (FEIS).

Patients and Methods: A total of 350 patients with first ever ischemic stroke (FEIS) admitted, within 24 hours of onset. Admission rates, risk factors, stroke severity, in hospital mortality and clinical and laboratory parameters on admission were compared in relation to different seasons.

Results: The admission rate for FEIS was highest in summer. Patients were more likely to be hypertensive during winter. The highest rate of cardiac diseases was found during winter. The most severe stroke was recorded during winter. Significantly, the highest value of leukocytic count and mean platelet volume and the lowest value of activated partial thromboplastin time were recorded during winter. The highest rates of inhospital mortality were reported during winter.

Conclusion: Seasonality has a paramount effect on first ever ischemic stroke. Different risk factors have different influences on ischemic stroke in relation to seasonality.

Keywords: - acute cerebral infarction - ischemic stroke - risk factors - seasonal variation in ischemic stroke
\end{abstract}

\section{Introduction}

An impact of climate upon cerebrovascular risk is both biologically conceivable and confirmed by epidemiological studies. These associations are worthy as they could produce public health policies to help protect the susceptible from the increased death rates arising during tremendous cold and heat waves ${ }^{(1)}$. The effect of Seasonality on stroke has been reported in several regions worldwide. Nevertheless, there is inadequate data 
related to these phenomena in other areas ${ }^{(2)}$. Data are incongruous as some studies determined higher stroke incidence during winter and spring and lower incidence during summer and autumn on the other hand no differences could be found in other studies ${ }^{(3)}$. Numerous trigger factors, such as hypercoagulable state, acute infections, and cold induced hypertension, as well as seasonal variations in serum lipids and glucose were discussed as possible clarifications for seasonality in vascular diseases ${ }^{(3)}$. The aim of the present study was to investigate the possible effect of seasonality on stroke severity and acute Ischemic stroke (AIS) risk factors impact in Sohag Governorate.

\section{Patients and Methods}

This is a descriptive study analyzing the relation between seasonality and first ever ischemic stroke (FEIS).The study was conducted in Sohag University Hospital. The Sohag Governorate extends from the southern edge of Assiut Governorate at latitude $26^{\circ} 57 \mathrm{~N}$ to the northern edge of Qena Governorate at latitude $26^{\circ} 07^{\prime} \mathrm{N}$. It forms a part of the Nile Valley, lying 62 meters above the sea level. The River Nile length in this area is $125 \mathrm{~km}$, and the width of the valley ranges between 16 and $20 \mathrm{~km}^{(4)}$. The Four seasons were defined as the following: winter (December through February) where the monthly temperature Ranging between $15^{\circ} \mathrm{c}$ and $16.5^{\circ} \mathrm{c}$ with a seasonal mean $16^{\circ} \mathrm{c}$, spring (March through May) where the monthly temperature Ranging between $19.7^{\circ} \mathrm{c}$ and $29.3^{\circ} \mathrm{c}$ with a seasonal mean $24.7^{\circ} \mathrm{c}$, summer (June through August)where the monthly temperature Ranging between $30.3^{\circ} \mathrm{C}$ and $31.5^{\circ} \mathrm{c}$ with aseasonal mean $30.8^{\circ} \mathrm{c}$, and autumn (September through November) where the monthly temperature Ranging between $26.4^{\circ} \mathrm{c}$ and $28.6^{\circ} \mathrm{C}$ with a seasonal mean $25.3^{\circ} \mathrm{c}$. Temperature variations in this region are greater than in the more northern parts of Egypt. Upper Egypt is characterized by an extreme desert climate ${ }^{(5)}$.
We followed the World Health Organization definition of stroke ${ }^{(6)}$. Inclusion criteria included every consecutive patient aged 18 years and older with first ever ischemic stroke (FEIS) admitted, within 24 hours of onset, to Neurology Department, Sohag University Hospital. The study

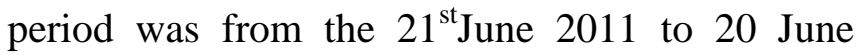
2013. Exclusion criteria included; residence outside Sohag governorate, patients with a transient ischemic attack (an event lasting <24 hours), died within 24 hrs of admission, a previous history of stroke, the diagnosis of stroke is uncertain, and a major illness causing prolonged bed rest. According to the previous criteria among 187 cases with first ever ischemic stroke admitted to the hospital during summer only 126 cases were from Sohag, another 54 cases were also excluded as a result of being diagnosed as having haemorhagic stroke (43 cases), TIAs (one case), or recurrent ischemic stroke (9 cases). In autumn and spring among 127 and 120 admitted cases only 99 and 71 cases were included respectively while the other cases were excluded due to either residence outside Sohag governorate or not meeting (FEIS) diagnosis. In winter also 54 cases only met our inclusion criteria from 121 admitted stroke cases. Subjects' data were registered and completed prospectively during their hospital stay up to discharge. Demographic and stroke risk factors were assessed. Hypertension was diagnosed if the patient was on antihypertensive medication on admission or in case of diastolic blood pressure $(\mathrm{DBP}) \geq 90 \mathrm{mmHg}$ and systolic blood pressure $(\mathrm{SBP}) \geq 140 \mathrm{mmHg}$. Diabetes mellitus was diagnosed in patients with fasting blood glucose level above $125 \mathrm{mg} / \mathrm{dl}$, with antidiabetics on admission or if a physician had previously made this diagnosis.

Hypercholesterolemia was diagnosed in patients with fasting cholesterol levels $\geq 200 \mathrm{mg} / \mathrm{dl}$ or LDL-cholesterol $\geq 140 \mathrm{mg} / \mathrm{dl}$ or with cholesterollowering medication on admission. On admission, the following clinical data were recorded: systolic and diastolic blood pressure, temperature, pulse rate, and complete medical and neurological 
examination. The severity of stroke was determined using the Canadian Stroke Scale (CSS). The in-hospital mortality was recorded. The following laboratory data were evaluated: blood sugar, serum creatinine, complete blood count, coagulation profile, lipid profile and liver functions test. CT brain was done for all patients, and MRI brain was done for some patients.

A specialist in physical geography (Dr M. Hegab) retrieved the meteorological data collected from the Egyptian Meteorological Authority on the day when each of the 350 acute ischemic strokes occurred.

\section{$\underline{\text { Statistical Analysis }}$}

Data were grouped, tabulated and statistically analyzed using the Statistical Package for the Social Sciences (SPSS version20). Descriptive statistics were used to compare the characteristics of each season. Continuous variables were expressed as mean (SD) or median (IQR), and categorical variables as percentages. Chi square test was used for detection of seasonal difference of categorical data while seasonal differences in the means of continuous measurements were tested by the One Way ANOVA test. A P-value of $<0.05$ was considered significant.

\section{$\underline{\text { Results }}$}

A total of 350 patients with FEIS were included in the study, of whom $213(60.8 \%)$ were females and $137(39.2 \%)$ were males. The mean age of the patients was $62.1 \pm 13.7$ years. For women the mean age was $61.4 \pm 13.7$ years and for men it was $63.21 \pm 13.7$ years. The weather parameters for the days included in this study are described in table 1 .

Distribution of cases regarding demographic data and vascular risk factors in different seasons are shown in table 2. No significant seasonal difference was found regarding age or sex. Patients were more likely to be hypertensive during winter $(\mathrm{P}=0.011)$. Also highly significant seasonal difference was found for history of cardiac diseases $(\mathrm{P}=0.002)$ the highest rate was found during winter.

Clinical findings in different seasons were shown in table 3. Significant seasonal difference was found for diastolic blood pressure $(\mathrm{P}$ value $=0.019$ ) with lowest values in spring and highest in summer. Stroke severity on admission measured by the Canadian Stroke Scale revealed significant seasonal difference with the most severe stroke in winter and the least severe in $\operatorname{autumn}(\mathrm{p}=0.03)$.

Laboratory findings on admission in different seasons are shown in table 4. A highly significant seasonal differences was shown for leukocyte count on admission ( $p=0.007$ ), with highest values during winter. Mean platelet volume (MPV) revealed a significant seasonal variation with highest value during winter $(\mathrm{p}=0.015)$. Also high statistically significant seasonal difference ( $\mathrm{p}$ $=0.0008$ ) was shown for activated partial thromboplastin time (aPTT) with the lowest value during winter.

Significant seasonal differences could be shown for in-hospital mortality, with highest rates during winter $(29.6 \%)$ and lowest rates during spring $(4.2 \%)(\mathrm{P}=0.001)$ (Figure 1). 
Table 1 Weather parameters for Sohag Governorate (from 21June 2011 to 20 June 2013)

\begin{tabular}{lllll}
\hline & Summer & Autumn & Winter & Spring \\
\hline Average temperature & $32.68 \pm 1.8$ & $24.35 \pm 5.1$ & $17.21 \pm 4.07$ & $30.04 \pm 4.7$ \\
Maximum temperature & $39.6 \pm 2.03$ & $31.6 \pm 5.5$ & $24.9 \pm 4.9$ & $37.5 \pm 4.9$ \\
Minimum temperature & $25.5 \pm 1.9$ & $17.4 \pm 5.06$ & $9.7 \pm 3.6$ & $21.8 \pm 4.4$ \\
Atmospheric pressure & $1005.6 \pm 2.01$ & $1013 \pm 2.8$ & $1016.54 \pm 3.9$ & $1009.4 \pm 2.9$ \\
Relative humidity & $1.83 \pm 0.59$ & $3.08 \pm 1.03$ & $3.21 \pm 1.09$ & $2.0 \pm 2.2$ \\
Precipitation & 0 & $0.02 \pm 0.14$ & 0 & $0.03 \pm 0.167$ \\
Vertical Visibility & 10 & 10 & $9.92 \pm 0.26$ & $9.9 \pm 0.167$ \\
Average wind velocity & $10.14 \pm 2.6$ & $7.3 \pm 3.1$ & $5.44 \pm 2.5$ & $8.2 \pm 3.5$ \\
Maximum wind velocity & $18.66 \pm 4.6$ & $15.0 \pm 5.7$ & $13.75 \pm 6.9$ & $15.82 \pm 5.8$ \\
\hline
\end{tabular}

Table 2: Distribution of cases concerning demographic data and vascular risk factors in different seasons

\begin{tabular}{|c|c|c|c|c|c|c|}
\hline season & Summer & Autumn & Winter & Spring & Total & P-value \\
\hline Cases no. (\%) & $\begin{array}{c}126 \\
(36.00 \%)\end{array}$ & $99(28.29 \%)$ & $54(15.43 \%)$ & $71(20.29 \%)$ & $350(100 \%)$ & \\
\hline Age mean $(S D)$ & $62.21(13.9)$ & $60.68(13.9)$ & $62.72(13.9)$ & $63.61(13.1)$ & & 0.57 \\
\hline $\begin{array}{l}\text { Sex no. }(\%) \\
\text { Female } \\
\text { Males }\end{array}$ & $\begin{array}{l}78(61.9 \%) \\
48(38.09 \%)\end{array}$ & $\begin{array}{l}54(54.54 \%) \\
45(45.45 \%)\end{array}$ & $\begin{array}{c}30(55.5 \%) \\
24(44.5 \%)\end{array}$ & $\begin{array}{l}42(59.2 \%) \\
29(40.8 \%)\end{array}$ & $\begin{array}{l}204(58.2 \%) \\
146(41.7 \%)\end{array}$ & 0.49 \\
\hline Hypertension no. (\%) & $52(41.27 \%)$ & $49(49.49 \%)$ & $35(64.81 \%)$ & $28(39.44 \%)$ & $164(46.8 \%)$ & 0.011 \\
\hline $\begin{array}{l}\text { Diabetes mellitus no. } \\
\text { (\%) }\end{array}$ & $37(29.37 \%)$ & $20(20.20 \%)$ & $19(35.19 \%)$ & $22(30.99 \%)$ & $98(28 \%)$ & 0.480 \\
\hline $\begin{array}{l}\text { Cardiac disease no. } \\
(\%)\end{array}$ & $14(11.11 \%)$ & $20(20.20 \%)$ & $21(38.89 \%)$ & $9(12.68 \%)$ & $64(18.28 \%)$ & 0.002 \\
\hline $\begin{array}{l}\text { Hyperlipidemia } n o . \\
(\%)\end{array}$ & $27(21.4 \%)$ & $32(32.3 \%)$ & $9(16.6 \%)$ & $12(16.9 \%)$ & $80(22.85 \%)$ & 0.051 \\
\hline
\end{tabular}

Table 3: Seasonality and clinical findings on admission

\begin{tabular}{llllll}
\hline Season & Summer & Autumn & Winter & Spring & P-Value \\
\hline Systolic BP, $M(S D)$ & $143.8(25.2)$ & $143.2(23.4)$ & $144.1(23.9)$ & $138.3(20.8)$ & 0.347 \\
$\begin{array}{l}\text { Diastolic BP, } M(S D) \\
\text { Clinical presentation }\end{array}$ & $87.60(13.3)$ & $84.49(11.1)$ & $86.60(12.1)$ & $82.25(11.5)$ & 0.019 \\
$\quad$ Disturbed & & & & & \\
$\quad$ Consciousness, \% & $31(24.6 \%)$ & $23(23.2 \%)$ & $21(38.8 \%)$ & $13(18.3)$ & 0.32 \\
$\quad$ & & & & \\
$\quad$ Weakness, \% & $105(83.3 \%)$ & $82(82.8 \%)$ & $47(87.0 \%)$ & $57(80.2 \%)$ & 0.56 \\
$\quad$ Speech Disturbances, \% & $12(9.5 \%)$ & $8(8.1 \%)$ & $3(5.5 \%)$ & $2(2.8 \%)$ & 0.3 \\
$\quad$ GCS & $12.32(3.2)$ & $12.96(2.6)$ & $12.29(2.6)$ & $12.70(2.5)$ & 0.33 \\
Stroke severity (CSS) $M(S D)$ & $5.9(3.5)$ & $6.65(3.5)$ & $4.96(2.8)$ & $5.44(3.3)$ & 0.03 \\
\hline
\end{tabular}

BP: blood pressure; M (SD): mean (standard deviation); GCS: Glasgow Coma Scale; CSS: Canadian Stroke Scale

Table 4: Seasonality and laboratory findings on admission

\begin{tabular}{llllll}
\hline & Summer & Autumn & Winter & Spring & P-value \\
\hline Blood sugar $M(S D)$ & $152.61(78.4)$ & $153.01(82.35)$ & $158.34(89.12)$ & $158.85(77.02)$ & 0.94 \\
Serum creatinine $M(S D)$ & $1.36(1.38)$ & $1.11(0.53)$ & $1.44(1.7)$ & $1.49(1.8)$ & 0.17 \\
RBCs $M(S D)$ & $5.02(0.97)$ & $8.56(34.75)$ & $4.72(0.99)$ & $4.71(0.84)$ & 0.49 \\
HGB $M(S D)$ & $13.03(1.97)$ & $12.93(2.07)$ & $12.71(2.7)$ & $12.42(1.86)$ & 0.23 \\
WBCs $M(S D)$ & $10.51(4.8)$ & $9.5(5.2)$ & $12.5(7.01)$ & $10.4(5.8)$ & 0.007 \\
Platelet count $M(S D)$ & $270.2(90.63)$ & $269.0(93.54)$ & $258.13(67.7)$ & $260.45(95.41)$ & 0.82 \\
MPV & $8.86(2.18)$ & $8.19(2.1)$ & $9.6(1.97)$ & $8.98(1.5)$ & 0.015 \\
INR $M(S D)$ & $1.16(0.24)$ & $1.23(0.46)$ & $1.14(0.12)$ & $1.18(0.19)$ & 0.36 \\
aPTT $M(S D)$ & $38.10(9.6)$ & $35.39(10.4)$ & $30.75(4.9)$ & $35.22(5.9)$ & 0.0008 \\
\hline
\end{tabular}

$M$ (SD): mean (standard deviation); RBCs: red blood corpuscles; HGB; hemoglobin; WBCs: white blood corpuscles; MPV: mean platelet volume; INR: international normalization ratio; aPTT: activated partial thromboplastin time 


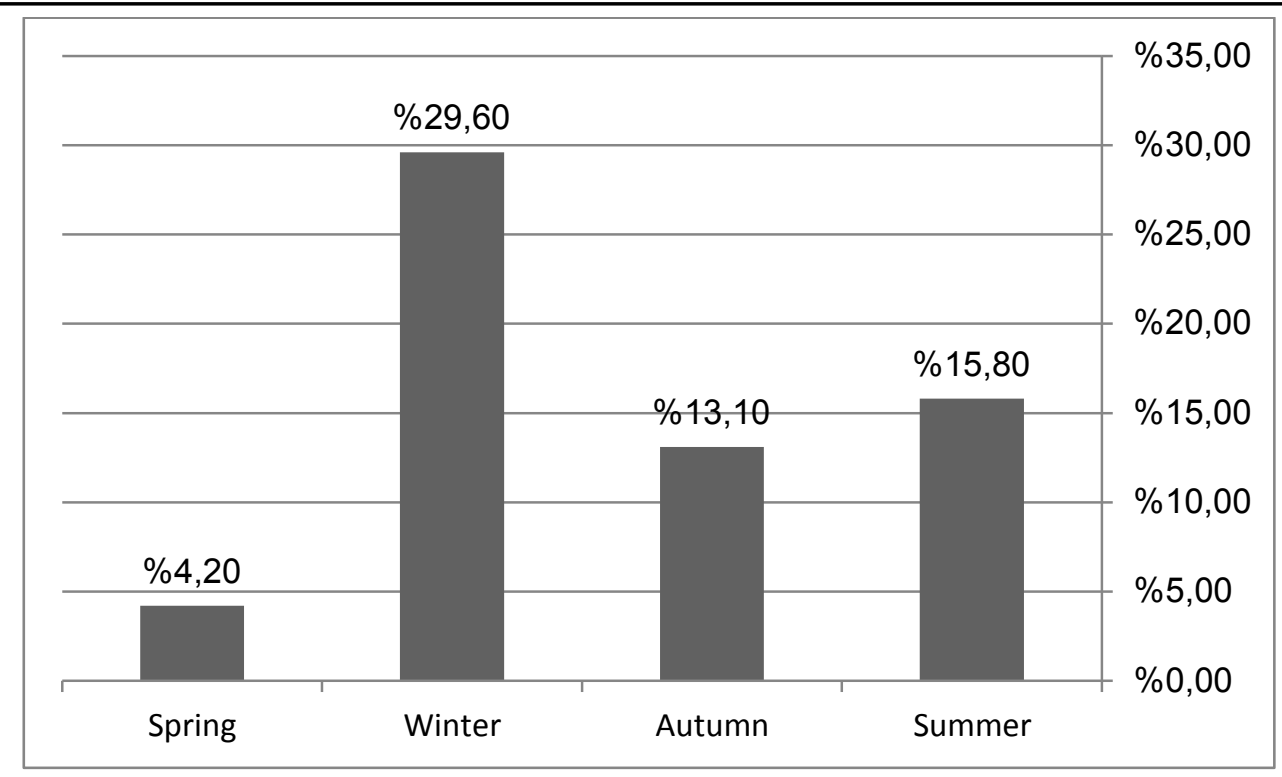

Figure 1 seasonality and in hospital mortality

\section{Discussion}

We analyzed the effect of seasonality on FEIS. The admission rate for FEIS was highest in summer and lowest in winter. Our findings are consistent with several previous studies ${ }^{(7,8)}$. The possible biological explanations for these observations is that, in hot environment, the body needs to raise heat diffusion through thermoregulatory mechanisms, such as sweating, vasodilatation, and elevating heart rates; so, blood supply to the brain may be decreased and existing ischemia may be aggravated ${ }^{(9)}$. Blood viscosity and cholesterol levels may also be increased by dehydration on hot days, which in turn increases the likelihood of microvascular thrombosis and subsequent stroke ${ }^{(1)}$.

On the other hand, our findings are not consistent with other studies, in which, the incidence of cerebrovascular stroke is significantly increased during winter ${ }^{(10,11)}$. From the biological point of view, no obvious explanation for the higher rate of ischemic stroke in winter; in spite of this, numerous mechanisms have been suggested, cold exposure can lead to vasoconstriction, which increases arterial pressure, raised cholesterol and triglyceride levels in winter ; and significant seasonal variations ( $\mathrm{SVs}$ ) in fibrinogen levels and plasma viscosity, seasonal patterns of infections are assumed to affect the SVs of cerebrovascular stroke hospitalization and mortality ${ }^{(2)}$.

In a multicenter hospital-based study, carried out in 24 centers, Chang et al ${ }^{(12)}$ grouped these centers into "cold centers" and "warm centers" in accordance with whether their minimum mean temperature in any given month ever reached lower than $5^{\circ} \mathrm{C}$ or not. Such categorization could partially solve the controversy between previous studies; i.e. cold areas have higher incidence of ischemic stroke in winter and warm areas have higher incidence of ischemic stroke in summer $(7,8,10,11)$.

Also vitamin D could solve another aspect of this controversy. Accumulating data implies that vitamin D deficiency is linked with increased risk of stroke. In northern countries at latitudes more than around $40^{\circ} \mathrm{N}$ (north of Madrid), sunlight is not adequately strong to activate synthesis of vitamin D in the skin from October to March ${ }^{(13)}$. We have a sunny winter and exposure to the sun is almost always better in winter than in summer as a tradition of our population, and this could explain the low rate of ischemic stroke admission in winter.

We have found SVs regarding the prevalence of hypertension, which was significantly lowest in 
spring and highest in winter. Also, we have found a SVs regarding DBP on admission, which was significantly lowest in spring and highest in summer and winter. This means that a better control of blood pressure occurring in spring, while winter and summer were associated with bad impact on blood pressure control. Seasonal effect on arterial blood pressure has been shown by various studies. A winter peak has been reported of both systolic and diastolic blood pressures, denoting seasonal effect on arterial blood pressure ${ }^{(14)}$. Recent data suggesting better control of blood pressure during summer in patients with hypertension support this thesis ${ }^{(15)}$. The above mentioned observations could be right for cold areas, in which summer is similar to the spring in our locality. however our finding of raised DBP on admission during summer in consistent with other studies that reported that, the DBP increased by $0.20 \mathrm{mmHg}$ due to a $1^{\circ} \mathrm{C}$ increase in the ambient temperature ${ }^{(16)}$. Another study reported that an elevation in personal-level environmental temperature of $1^{\circ}$ Celsius was associated with a $0.81-1.44 \mathrm{~mm} \mathrm{Hg}$ and $0.59-0.83$ $\mathrm{mm} \mathrm{Hg}$ increase in systolic and diastolic BP, respectively ${ }^{(17)}$.

The highest rate of cardiac diseases was found during winter and the lowest was found during summer. This could suggest that ischemic stroke secondary to cardiac disease is more likely to occur during winter. Winter peaks in cardiac events and stroke have been reported in different region of the world ${ }^{(2)}$. Fustinoni and colleagues found a marked SVs in the frequency of cases with $\mathrm{AF}$, with a peak in winter and a valley in summer. They also reported that, low ambient temperatures enhancing sympathetic function by stimulation of central angiotensin or hypothalamic receptors for mineralocorticoids could cause episodes of $\mathrm{AF}^{(18)}$.

In spite of the low rate of ischemic stroke admission in winter observed in our study; stroke severity and in hospital mortality are significantly higher in winter. Our findings are in agreement with Sheth and colleagues, who reported that patients who suffer a stroke in the winter have a substantially worse prognosis than patients who have a stroke at other times of the year, particularly if they are older ${ }^{(19)}$. Regarding stroke severity, our finding is consistent with Palm and colleagues who reported that stroke severity is higher in winter and autumn and lower in summer (3). Contrary to this previous study we have found that stroke severity was lower in autumn. However this study was done in cold area, in which summer's climate is similar to autumn in our locality. Regarding our findings of the seasonal variation of in hospital mortality which was highest in winter, several previous studies reported increased stroke mortality in winter ${ }^{(3)}$. We did not asses the level of fibrinogen in our subjects, however two laboratory parameters in our study could suggest a SVs of hypercoagulability with peaks in winter; the first is aPTT which was significantly lower in winter and the second is MPV which was significantly higher in winter. Woodhouse and colleagues ${ }^{(20)}$ reported that higher fibrinogen activity in winter provide further possible explanations for the marked seasonal variation in death from ischaemic heart disease and stroke.

The winter peak of leukocytic count found among our subjects suggests a SVs of infections during winter. This finding in agreement with previous studies which reported that, stroke risk temporally increases by acute infections, and these infections show characteristic SVs with higher incidence in winter and spring and lower incidence in summer.

Our study has a number of limitations. Being a hospital based, our study may be subjected to referral bias. Some of the risk factors such as fibrinogen level, infections and air pollution were not analyzed. Our subjects were not categorized into age groups as climatic factors have different impact on different age groups.

In conclusion seasonality has a paramount effect on first ever ischemic stroke. The highest rate of admission was found during summer, while the 
worst prognosis, including the highest rate of inhospital mortality, was found during winter. Different risk factors have different influences on ischemic stroke in relation to seasonality. Further studies are needed to unmask the complex effect of seasonality on ischemic stroke.

\section{References}

1. McArthur K, Dawson J, Walters M. What is it with the weather and stroke? Expert review of neurotherapeutics. 2010;10(2):243-9. Epub 2010/02/09.

2. Diaz A, Gerschcovich ER, Diaz AA, Antia F, Gonorazky S. Seasonal variation and trends in stroke hospitalizations and mortality in a South American community hospital. Journal of stroke and cerebrovascular diseases : the official journal of National Stroke Association. 2013;22(7):e66-9. Epub 2012/05/23.

3. Palm F, Dos Santos M, Urbanek C, Greulich M, Zimmer K, Safer A, et al. Stroke seasonality associations with subtype, etiology and laboratory results in the Ludwigshafen Stroke Study (LuSSt). European journal of epidemiology. 2013;28(5):373-81. Epub 2013/02/07.

4. Ahmed A. Using Generic and Pesticide DRASTIC GIS-based models for vulnerability assessment of the Quaternary aquifer at Sohag, Egypt. Hydrogeol J. 2009;17(5):1203-17.

5. Programme S. SOHAG GOVERNORATE ENVIRONMENTAL PROFILE,

Ministry of State for Environmental Affairs. 2007.

6. Hatano S. Experience from a multicentre stroke register: a preliminary report. Bulletin of the World Health Organization. 1976;54(5):541-53. Epub 1976/01/01.

7. Dawson J, Weir C, Wright F, Bryden C, Aslanyan S, Lees K, et al. Associations between meteorological variables and acute stroke hospital admissions in the west of Scotland. Acta neurologica Scandinavica. 2008;117(2):85-9. Epub 2008/01/11.

8. Giua A, Abbas MA, Murgia N, Corea F. Climate and stroke: a controversial association. International journal of biometeorology. 2010;54(1):1-3. Epub 2009/08/27.

9. Chen R, Wang C, Meng X, Chen $\mathrm{H}$, Thach TQ, Wong CM, et al. Both low and high temperature may increase the risk of stroke mortality. Neurology. 2013;81(12):106470. Epub 2013/08/16.

10. Wang Y, Levi CR, Attia JR, D'Este CA, Spratt N, Fisher J. Seasonal variation in stroke in the Hunter Region, Australia: a 5-year hospital-based study, 1995-2000. Stroke; a journal of cerebral circulation. 2003;34(5):1144-50. Epub 2003/04/05.

11. Diaz-Tapia V, Billeke P, Bustos C, Lopez $\mathrm{M}$, Segovia D. [Seasonal variations in the symptoms of cerebrovascular disease. A study of hospital admission rates]. Revista de neurologia. 2004;39(12):1196-7. Epub 2004/12/31. Variaciones estacionales en la presentacion de la enfermedad cerebrovascular. Estudio de tasas de hospitalizacion.

12. Chang CL, Shipley M, Marmot M, Poulter N. Lower ambient temperature was associated with an increased risk of hospitalization for stroke and acute myocardial infarction in young women. Journal of clinical epidemiology. 2004;57(7):749-57. Epub 2004/09/11.

13. O'Connor A, Benelam B. An update on UK Vitamin D intakes and status, and issues for food fortification and supplementation. Nutrition Bulletin. 2011;36(3):390-6.

14. Deshmukh A, Pant S, Kumar G, Murugiah $\mathrm{K}$, Mehta J. Seasonal variation in hypertensive emergency hospitalization. J Clin Hypertens (Greenwich). 2012;14(4):269-70. Epub 2012/03/31. 
15. Fletcher RD, Amdur RL, Kolodner R, McManus C, Jones R, Faselis C, et al. Blood pressure control among US veterans: a large multiyear analysis of blood pressure data from the Veterans Administration health data repository. Circulation. 2012;125(20):2462-8. Epub 2012/04/21.

16. Kim YM, Kim S, Cheong HK, Ahn B, Choi K. Effects of heat wave on body temperature and blood pressure in the poor and elderly. Environmental health and toxicology. 2012;27:e2012013. Epub 2012/08/14.

17. Brook RD, Shin HH, Bard RL, Burnett RT, Vette A, Croghan C, et al. Can personal exposures to higher nighttime and early-morning temperatures increase blood pressure? J Clin Hypertens (Greenwich). 2011;13(12):881-8. Epub 2011/12/07.

18. Fustinoni O, Saposnik G, Esnaola y Rojas MM, Lakkis SG, Sposato LA. Higher frequency of atrial fibrillation linked to colder seasons and air temperature on the day of ischemic stroke onset. Journal of stroke and cerebrovascular diseases : the official journal of National Stroke Association. 2013;22(4):476-81. Epub 2013/04/09.

19. Sheth T, Nair C, Muller J, Yusuf S. Increased winter mortality from acute myocardial infarction and stroke: the effect of age. Journal of the American College of Cardiology. 1999;33(7):1916-9. Epub 1999/06/11.

20. Woodhouse PR, Khaw KT, Plummer M, Foley A, Meade TW. Seasonal variations of plasma fibrinogen and factor VII activity in the elderly: winter infections and death from cardiovascular disease. Lancet. 1994;343(8895):435-9. Epub 1994/02/19. 